\title{
Transcriptomic and metabolomic analysis reveals the role of $C O A$ in the salt tolerance of Zygophyllum spp
}

\author{
Jie Wang ${ }^{1,2,3}$, Xi Jiang ${ }^{4}$, Chufeng Zhao ${ }^{5}$, Zhongming Fang ${ }^{6}$ and Peipei Jiao ${ }^{1,2^{*}}$
}

\begin{abstract}
Background: Zygophyllum is an important medicinal plant, with notable properties such as resistance to salt, alkali, and drought, as well as tolerance of poor soils and shifting sand. However, the response mechanism of Zygophyllum spp. to abiotic stess were rarely studied.

Results: Here, we aimed to explore the salt-tolerance genes of Zygophyllum plants by transcriptomic and metabolic approaches. We chose $Z$. brachypterum, Z. obliquum and Z. fabago to screen for salt tolerant and sensitive species. Cytological observation showed that both the stem and leaf of $Z$. brachypterum were significantly thicker than those of $Z$. fabago. Then, we treated these three species with different concentrations of $\mathrm{NaCl}$, and found that $Z$. brachypterum exhibited the highest salt tolerance (ST), while $Z$. fabago was the most sensitive to salt (SS). With the increase of salt concentration, the CAT, SOD and POD activity, as well as proline and chlorophyll content in SS decreased significantly more than in ST. After salt treatment, the proportion of open stomata in ST decreased significantly more than in SS, although there was no significant difference in stomatal number between the two species. Transcriptomic analysis identified a total of 11 overlapping differentially expressed genes (DEGs) in the leaves and roots of the ST and SS species after salt stress. Two branched-chain-amino-acid aminotransferase (BCAT) genes among the $11 \mathrm{DEGs}$, which were significantly enriched in pantothenate and CoA biosynthesis, as well as the valine, leucine and isoleucine biosynthesis pathways, were confirmed to be significantly induced by salt stress through qRT-PCR. Furthermore, overlapping differentially abundant metabolites showed that the pantothenate and CoA biosynthesis pathways were significantly enriched after salt stress, which was consistent with the KEGG pathways enriched according to transcriptomics.

Conclusions: In our study, transcriptomic and metabolomic analysis revealed that BCAT genes may affect the pantothenate and CoA biosynthesis pathway to regulate the salt tolerance of Zygophyllum species, which may constitute a newly identified signaling pathway through which plants respond to salt stress.
\end{abstract}

Keywords: Zygophyllum, Salt stress, Transcriptomics, Metabolomics, Branched-chain-amino-acid aminotransferase, COA

\section{Background}

Soil salinization has become an important global ecological and environmental problem, and the salinized soil affects the geographical distribution of plants, restricts their productivity, and threatens food security [1]. High salt levels can cause secondary stresses such as ion

\footnotetext{
*Correspondence: jiaopeipei2000@126.com

${ }^{1}$ Key Laboratory of Biological Resource Protection and Utilization of Tarim Basin, Xinjiang Production and Construction Group, Alar 843300, China

${ }^{2}$ College of Life Sciences, Tarim University, Alar 843300, China

Full list of author information is available at the end of the article
}

toxicity, hyperosmolar stress and oxidative damage, which seriously affect the growth and development of plants [2]. To adapt to the salinized environment, plants initiate a series of regulatory mechanisms to reduce salt damage, including morphological changes $[3,4]$, osmotic regulation in cells $[5,6]$, scavenging of reactive oxygen species [7], excretion and intracellular compartmentalization of salts $[8,9]$, regulation of potassium transport $[10,11]$, regulation of aquaporin expression [12, 13], and changes in the rate of photosynthesis [14].

(c) The Author(s). 2020 Open Access This article is distributed under the terms of the Creative Commons Attribution 4.0 International License (http://creativecommons.org/licenses/by/4.0/), which permits unrestricted use, distribution, and 
To understand the molecular mechanisms of plant salt tolerance, many researchers focused on screening salttolerant species to obtain salt-tolerance genes. Recently, increasing numbers of studies have elucidated the salt stress signal transduction pathways of plants, which are important for the comprehensive understanding of the molecular mechanisms of plant salt tolerance. Abscisic acid (ABA) plays a key role in optimizing plant water use, and it is essential for seed development and responses to drought, high salinity and other environmental stresses [15]. ABA is widely believed to be involved in osmotic stress signal transduction under salt stress [16]. Protein phosphorylation is a central feature of eukaryotic signal transduction, and it also plays a role in osmotic stress adaptation [2]. The mitogen-activated protein kinase (MAPK) pathway not only participates in plant growth and development processes, but can also be activated by a number of different biological and abiotic stresses, such as high salt, drought, and cold stress [17, 18]. The salt overly sensitive (SOS) signaling pathway is responsible for $\mathrm{Na}^{+}$excretion in plant root cells, which is one of the best-studied mechanisms of plant salt tolerance. In this pathway, three SOS genes (SOS1, SOS2 and SOS3) are involved in mediating the signals that regulate the intracellular ion balance [19-22].

Zygophyllum is a genus whose members are mainly distributed in desert and semi-desert areas, and consequently have a strong ability to adapt to salt and drought stress. Therefore, Zygophyllum plants have important genetic resources that protect them from abiotic stresses, especially salt stress. Furthermore, Zygophyllum plants are considered to be early colonizers of soils polluted with heavy metals under semiarid conditions, and they have broad-spectrum resistance to heavy metals such as $\mathrm{Pb}, \mathrm{Zn}$ and $\mathrm{Cu}[23,24]$. To date, there were only a few studies on the basic biology of Zygophyllum, and systematic investigations of its unique salt-tolerance characteristics at the seedling stage are extremely limited. In this study, the salt tolerance of three Zygophyllum species ( $Z$. brachypterum, $Z$. obliquum and $Z$. fabago) was assessed to screen the salt-tolerant and saltsensitive species. Then, transcriptomic and metabolomic analyses were performed to identify the genes and metabolic pathways involved in salt tolerance. The results showed that two branched-chain-amino-acid aminotransferase (BCAT) genes, which were the most likely candidate genes to respond to salt stress, might affect the CoA biosynthesis pathway to regulate the salt tolerance of Zygophyllum species.

\section{Results}

Anatomical differences of three Zygophyllum species When plants adapt to a saline soil, their morphology also changes. We analyzed the anatomical structure of main stems and leaves of $Z$. brachypterum, $Z$. obliquum and $Z$. fabago under the conditions of the natural environment. The results demonstrated that the pith area of the main stem of $Z$. brachypterum was the largest of the three species, while that of $Z$. fabago was the smallest (Fig. 1a-c). The leaves of $Z$. fabago were the thinnest among the three species, while no significant difference was found between $Z$. brachypterum and $Z$. obliquum (Fig. 1d-f). Statistical analysis showed that the thicknesses of the xylem, phloem and cortex of $Z$. brachypterum were all significantly larger than those of Z. fabago (Fig. 1g), in accordance with the thickest stem of $Z$. brachypterum and the thinnest stem of $Z$. fabago (Fig. 1f). In addition, the leaves of $Z$. brachypterum and $Z$. obliquum were significantly thicker than those of $Z$. fabago (Fig. 1i), which indicated that the leaves of $Z$. brachypterum and $Z$. obliquum might have a higher water storage capacity. These results indicated that $Z$. brachypterum plants might have a higher capacity to transport water from the stems and store it in the leaves than Z. fabago.

\section{Salt resistance of the three Zygophyllum species}

As desert plants, Zygophyllum spp. have good resistance against abiotic stresses. To discover the differences in salt stress tolerance among the three Zygophyllum species, we treated seedlings of Z. brachypterum, Z. obliquum and $Z$. fabago with $50 \mathrm{NaCl}, 100 \mathrm{NaCl}, 150 \mathrm{NaCl}$ and $200 \mathrm{mM} \mathrm{NaCl}$, or left them untreated (control, CK). Compared with the control group, the leaves of the three Zygophyllum species all showed different degrees of wilting as the salt concentration increased, whereby the degree of leaf wilting was the highest in Z. fabago and lowest in $Z$. brachypterum (Fig. 2a and b). Moreover, seedling growth of $Z$. obliquum and $Z$. fabago was significantly inhibited by $50 \mathrm{mM} \mathrm{NaCl}$ (Fig. 2a). With the further increase of salt concentration, the seedlings began to die, and the plant survival rate was dramatically decreased in Z. fabago (Fig. 2a and c). Conversely, the seedling survival rate of $Z$. brachypterum was the highest, even when the $\mathrm{NaCl}$ concentration was increased above $150 \mathrm{mM}$ (Fig. 2c). These results showed that $Z$. brachypterum had the strongest tolerance to salt stress, while $Z$. fabago had the weakest salt tolerance.

Under salt stress, a number of physiological indices are usually affected in plants, such as the proline, malondialdehyde (MDA) and chlorophyll content, as well as superoxide dismutase (SOD), catalase (CAT) and peroxidase (POD) activity. Two weeks after the final treatment with $\mathrm{NaCl}$, we measured these physiological indices in the three Zygophyllum species at different salt concentrations. The results showed that the MDA content decreased dramatically with the increase of salt concentration, especially in $Z$. brachypterum and $Z$. 

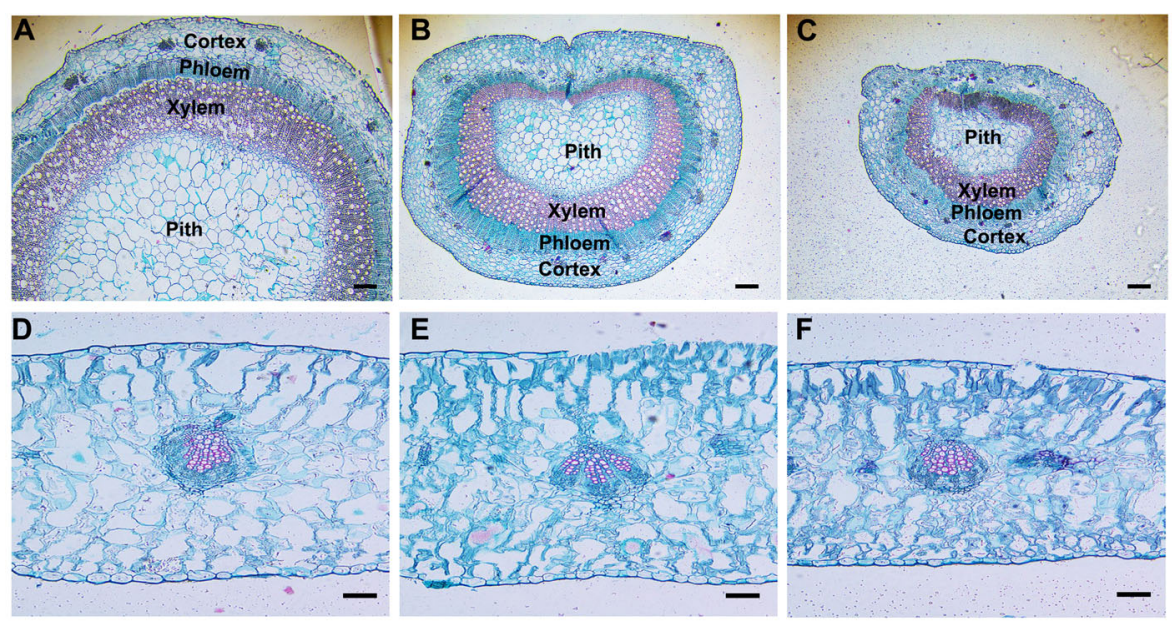

$\mathbf{F}$
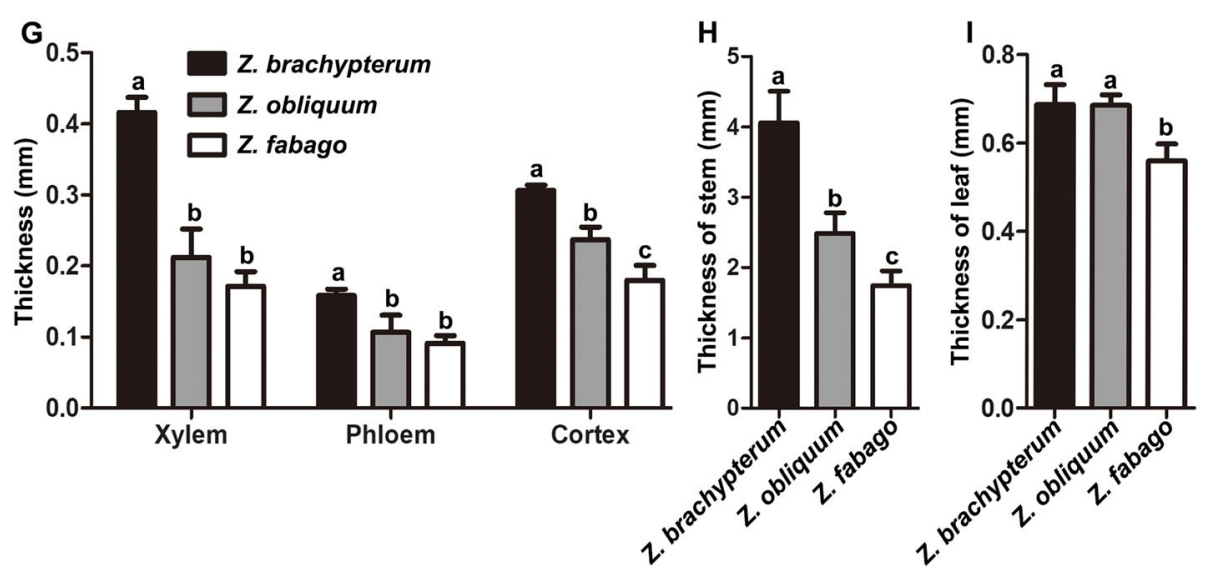

Fig. 1 Histological analysis of three Zygophyllum species. Cross section analysis of the main stem of Zygophyllum brachypterum (a), Zygophyllum obliquum (b) and Zygophyllum fabago (c). Cross section analysis of the leaf of Zygophyllum brachypterum (d), Zygophyllum obliquum (e) and Zygophyllum fabago (f). Statistical analysis of the thickness of main stem xylem, phloem and cortex (g). Statistical analysis of the thickness of the main stem (h) and leaf (i). Scale bars $=0.2 \mathrm{~mm}$ in (a), (b) and (c). Scale bars $=0.1 \mathrm{~mm}$ in (d), (e) and (f). Values are the means \pm SD from three replicates. Different letters indicate significant differences at $P<0.05$ according to Duncan's multiple range test

obliquum, but more slowly in Z. fabago (Fig. 3a). However, the chlorophyll content decreased dramatically in $Z$. fabago and the decrease was slowest in Z. brachypterum (Fig. 3b). The proline content increased significantly in Z. brachypterum when the salt concentration was higher than $100 \mathrm{mM}$, while in Z. obliquum it increased significantly when the salt concentration was higher than $150 \mathrm{mM}$. The degree of increase was not as great as that of $Z$. brachypterum. Interestingly, the proline content in $Z$. fabago decreased significantly when the salt concentration was higher than $150 \mathrm{mM}$ (Fig. 3c). CAT activity decreased with the increase of salt concentration in all the Zygophyllum species, whereby the reduction was the largest in $Z$. fabago and smallest in $Z$. brachypterum (Fig. $3 \mathrm{~d}$ ). The reduction of SOD and POD activity was also largest in $Z$. fabago, while no significant difference was found in either $Z$. brachypterum or $Z$. obliquum among the groups treated with different $\mathrm{NaCl}$ concentrations (Fig. 3e and f). These results indicated that $Z$. brachypterum was the most salt-tolerant (ST) species, while $Z$. fabago was the most salt-sensitive (SS).

\section{Salt induced stomatal closure in the ST species}

Stomatal movement regulates photosynthesis and transpiration, and plays an important role in regulating plant growth and development in response to abiotic stresses such as salt and drought. To understand the difference of stomatal movement after salt treatment between the ST and SS species, we treated ST and SS seedlings (10leaf stage) with $150 \mathrm{mM} \mathrm{NaCl}$ for $24 \mathrm{~h}$, after which leaves from the same position on the main stem were selected to perform scanning electron microscopy (SEM). The results demonstrated that there was no significant difference in the number of stomata per square millimeter between the salt treatment group and the control group of either species (Fig. 4a-e). We also measured the percentage of open stomata in the control and salttreated groups of the ST and SS species. The results 


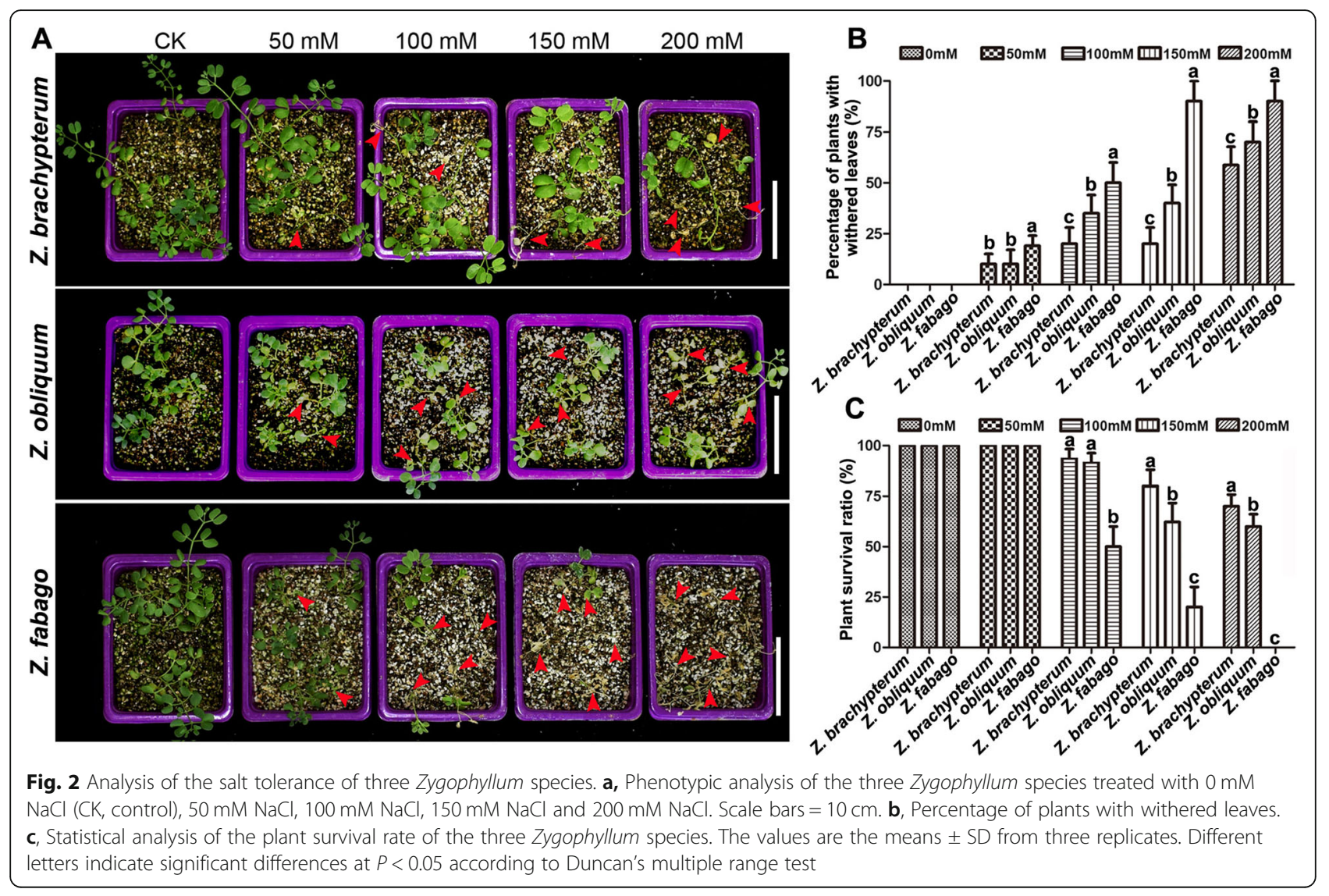

showed that open stomata accounted for $80 \%$ of the total in the control group but only $20 \%$ in the salttreated group of the ST species. By contrast, open stomata still accounted for $80 \%$ of the control group but $60 \%$ in the salt-treated group of the SS species (Fig. 4f). These results indicated that a sharp decrease in the ratio of open stomata was conducive to the retention of water in the leaves of the ST species under salt stress.

\section{Analysis of differentially expressed genes (DEGs) between the ST and SS species}

In order to reveal the mechanism underlying the difference of salt tolerance between the ST and SS species, 24 RNA-seq libraries containing three biological replicates, stratified by the absence or presence of $150 \mathrm{mM} \mathrm{NaCl}$ treatment, were constructed from roots and leaves. The high-throughput RNA-seq generated 43.8 to 65.2 million raw reads for each sample (Additional file 1: Table S1). After removing reads containing adapters, reads containing ploy- $\mathrm{N}$ and low-quality reads from the raw data, the number of clean reads was higher than 42.7 million for each sample. About $62.63-83.73 \%$ of the clean reads from each sample were mapped to the Arabidopsis reference genome using RSEM software (Additional file 1: Table S1). Using the Trinity platform, 498,605 unigenes were reassembled from the clean reads. The length of all unigenes varied from 201 to $37,056 \mathrm{bp}$, with an average length of $1038 \mathrm{bp}$ (Additional file 1: Table S2). The size distribution of the unigenes is illustrated in Additional file 1: Figure S1. The constructed unigene dataset was used as reference for further analysis, and was deposited with the national center for biotechnology information (NCBI).

DEGs between the control and $\mathrm{NaCl}$-treated groups were analyzed using the $\mathrm{R}$ package DESeq2 based on the criteria $P<0.05$ and $\mid \log 2$ FoldChange $\mid>1$. Compared to the control group, there were 8088 and 5272 DEGs in the leaves, as well as 10,392 and 66,743 DEGs in the roots of the salt-treated groups of the ST and SS species (Additional file 1: Figure S2). A total of 322 overlapping DEGs in the leaves and 4178 in the roots were found both in the ST and SS plants after salt treatment, compared to each control group (Fig. 5a). The expression of many DEGs was decreased or induced after salt treatment, both in leaves (Additional file 1: Figure S3A) and roots (Additional file 1: Figure S4A). GO term analysis showed that the DEGs in the leaves were mostly enriched in molecular functions, including sequencespecific DNA binding, nucleic acid binding transcript, and transcription factor activity (Additional file 1: Figure S3B), while those from roots were mostly enriched in cellular component categories such as cell, cell part and intracellular (Additional file 1: Figure S4B). KEGG 

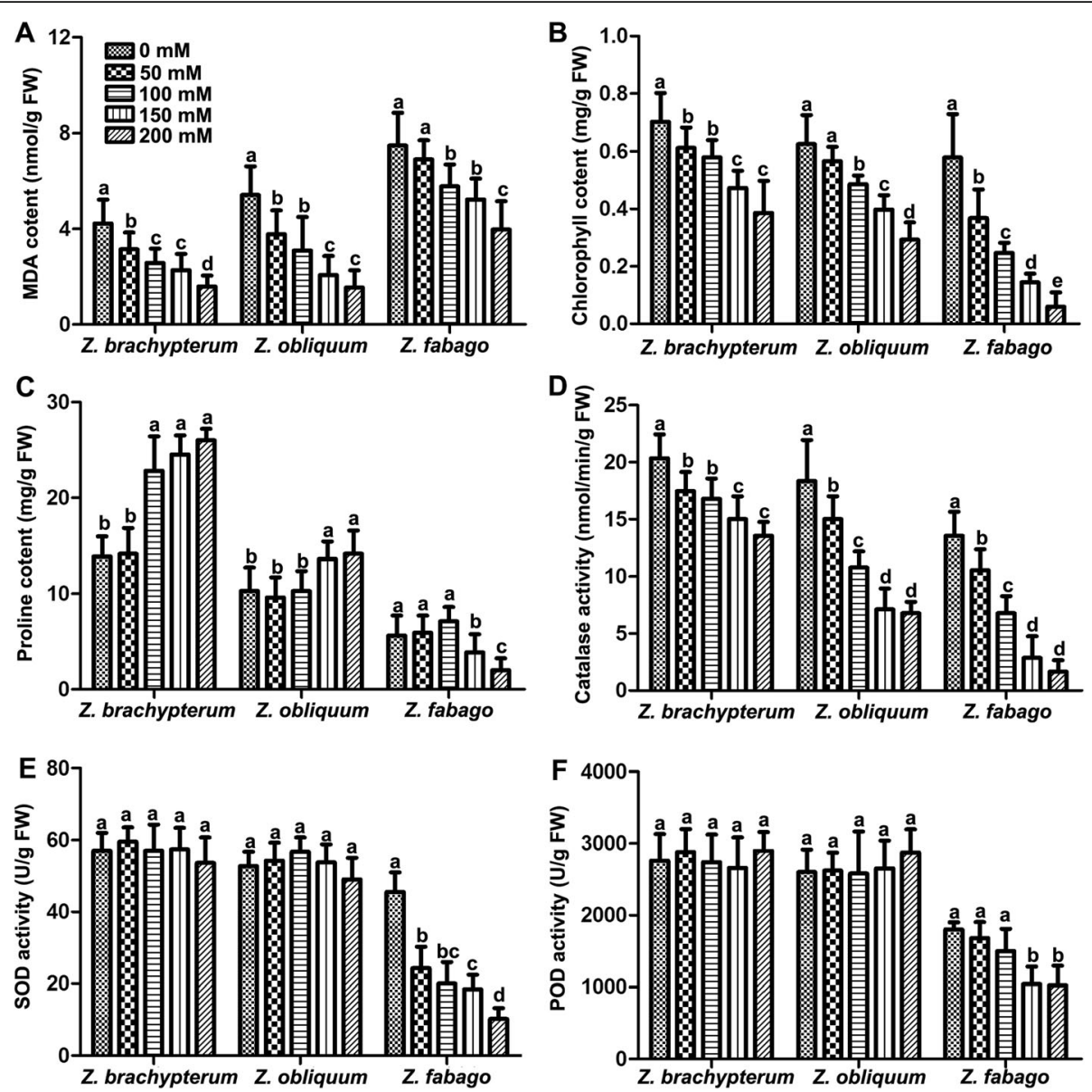

Fig. 3 Determination of physiological indices of the three Zygophyllum species under salt stress. MDA content (a), chlorophyll content (b), proline content (c), CAT activity (d), SOD activity (e) and POD (f) activity in leaves of three Zygophyllum species treated with different concentrations of $\mathrm{NaCl}$. The values are the means \pm SD from three replicates. Different letters indicate significant differences at $P<0.05$ according to Duncan's multiple range test

pathway enrichment analysis indicated that the DEGs in the leaves significantly affected plant hormone signal transduction, nitrogen metabolism, as well as glyoxylate and dicarboxylate metabolism (Additional file 1: Figure S3C), while only plant hormone signal transduction was significantly affected in the roots (Additional file 1: Figure S4C). Additionally, expression of some DEGs was validated by qRT-PCR both in leaves (Additional file 1 : Figures S5A and B) and roots (Additional file 1: Figure S5C and D), and the results showed that the expression level of over $90 \%$ genes was consistent with the FPKM values of RNA-seq. These results indicated that the DEGs might affect phytohormones levels in the roots and leaves, which in turn affected the salt tolerance of Zygophyllum plants.

\section{Candidate salt tolerance genes of Zygophyllum}

To further screen candidate genes responsible for salt tolerance, we combined the DEGs between the treatment and control groups in the roots and leaves. There were only 11 overlapping DEGs in roots and leaves, which exhibited different expression patterns (Fig. 5a and b). Among them, the expression of two genes (Cluster-113, 084.52599 and Cluster-113,084.52595) was higher in both leaves and roots of the salt treatment groups than in the corresponding control groups (Fig. 5b), which indicated that these two genes were induced by salt, especially in the SS species. The gene function annotation indicated that both Cluster-113,084.52599 and Cluster-113, 084.52595 encoded branched-chain amino acid aminotransferases (BCAT, Table 1). GO term analysis revealed that the 11 overlapping DEGs were mostly enriched in biological processes, especially in metabolism (Fig. 5c). KEGG pathway analysis demonstrated that 2 BCAT genes of the 11 overlapping DEGs were significantly enriched in valine, leucine and isoleucine biosynthesis, as well as the pantothenate and CoA biosynthesis pathways (Table 1 and Fig. 5c). To validate the expression levels of the 11 overlapping DEGs, qRT-PCR was performed. The results revealed that the expression trends of these genes in 

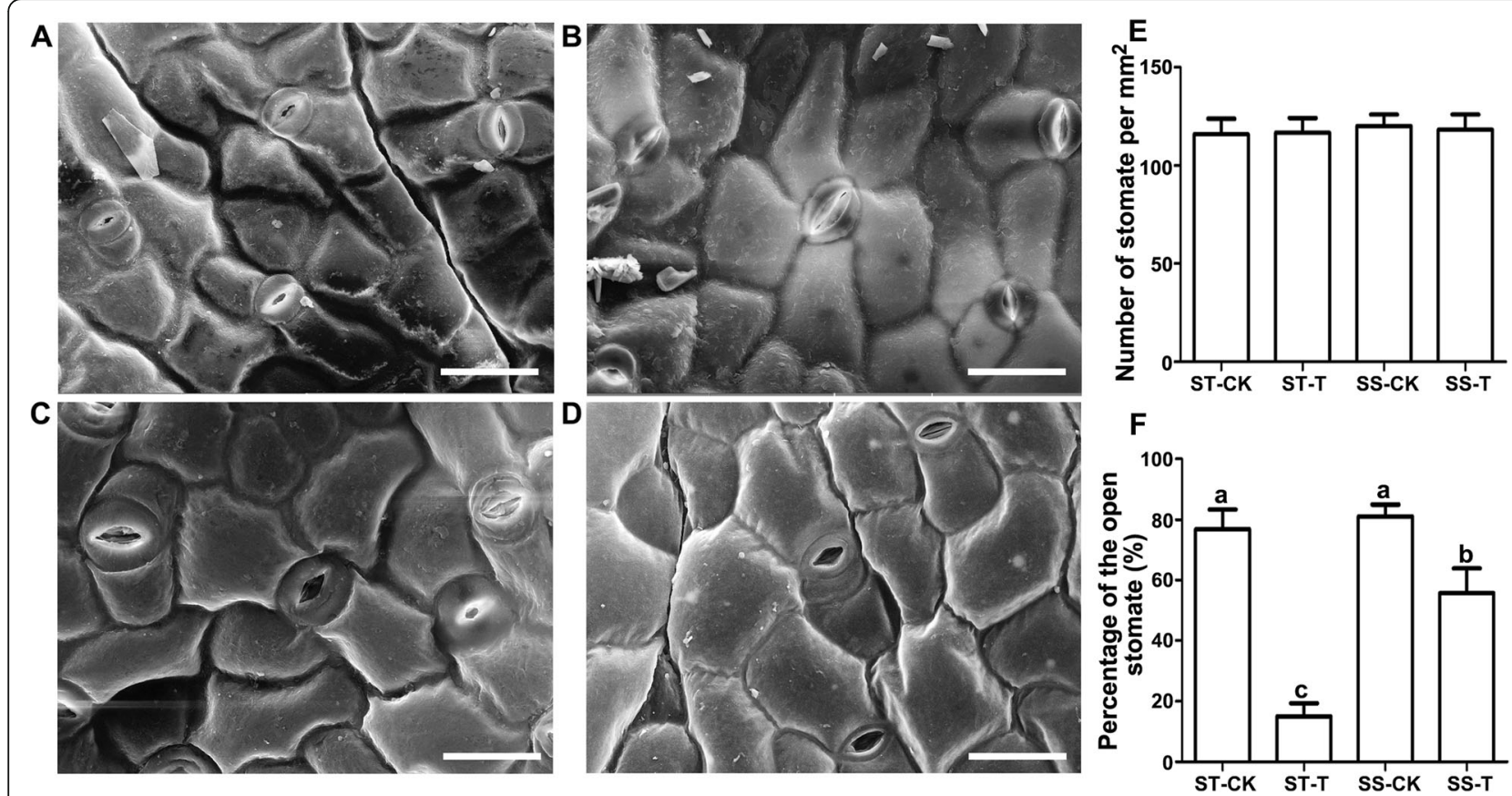

Fig. 4 SEM analysis of the differences of the leaf epidermis between the ST and SS Zygophyllum species. Seedlings at the 10-leaf stage were treated with $150 \mathrm{mM} \mathrm{NaCl}$ for $24 \mathrm{~h}$, after which their leaf epidermis was observed by SEM. Leaf epidermis of the ST species after treatment with 0 $\mathrm{mM}(\mathbf{a})$ and $150 \mathrm{mM} \mathrm{NaCl}$ (b). Leaf epidermis of the SS species after treatment with $0 \mathrm{mM}$ (c) and $150 \mathrm{mM} \mathrm{NaCl}$ (d). Statistical analysis of the number of stomata (e) and the percentage of open stomata (f). Scale bars $=50 \mu \mathrm{m}$ in $(\mathbf{a}-\mathbf{d})$. The values are the means \pm SD from three replicates. Different letters indicate significant differences at $P<0.05$ according to Duncan's multiple range test. The absence of marked significance in $\mathbf{e}$ indicates that there were no significant differences between any of the groups

different groups were consistent with the FPKM values of RNA-seq. Moreover, the two BCAT genes were strongly induced by salt stress, and the highest expression was observed in the SS species (Fig. 6). Taken together, the results indicate that the two BCAT genes might be candidate genes that play key roles in the regulation of salt tolerance in Zygophyllum by affecting the biosynthesis of valine, leucine and isoleucine, as well as pantothenate and CoA.

\section{Metabolomic analysis of differences between the ST and SS species}

As GO term analysis of the 11 common DEGs between ST and SS showed that metabolic processes were significantly enriched, we compared the metabolic profiles of the leaves of the SS and ST species under control and 150 $\mathrm{mM} \mathrm{NaCl}$ stress conditions. In order to ensure the reliability of the experimental data and results, we conducted 6 repetitions for each group. A total of 315 metabolites could be identified in all samples from the ST and SS species. According to the principal component analysis (PCA), there was an obvious separation between samples within treatments and the controls of the SS and ST species (Fig. 7a). Compared to the control group, a total of 70 and 55 differentially abundant metabolites were identified in leaves of the ST and SS salt-treated groups, among which 8 overlapping upregulated and 11 overlapping downregulated metabolites between the ST and SS salttreated groups were identified (Fig. 7b and c). Additionally, another 9 differentially abundant metabolites exhibited the opposite regulation pattern between the ST and SS species (Fig. 7d). Subsequent KEGG analysis based on the 28 overlapping differentially abundant metabolites showed that the pantothenate and CoA biosynthesis pathway was significantly enriched (Fig. 7e). Under salt stress, an important intermediate of CoA synthesis, 3-methyl-2oxobutanoate, was significantly upregulated in the ST, but downregulated in the SS species (Additional file 1: Figure S6A). Additionally, valine, which can be produced from 3methyl-2-oxobutanoate under the action of BCATs, was significantly upregulated in the SS species under salt stress (Additional file 1: Figure S6B). There was no significant difference in the CoA content between the ST salt-treated group and the corresponding control group, while the CoA content of the SS salt-treated group was significantly downregulated (Additional file 1: Figure S6C), which indicated that the CoA content was very important for Zygophyllum salt tolerance.

To identify DEGs that were functionally related with leaf physiological characteristics, two groups of correlation analysis (ST salt-treated vs. ST control and SS salttreated vs. SS control) between 134 DEGs and 42 metabolites were performed in this study. The coordinated 


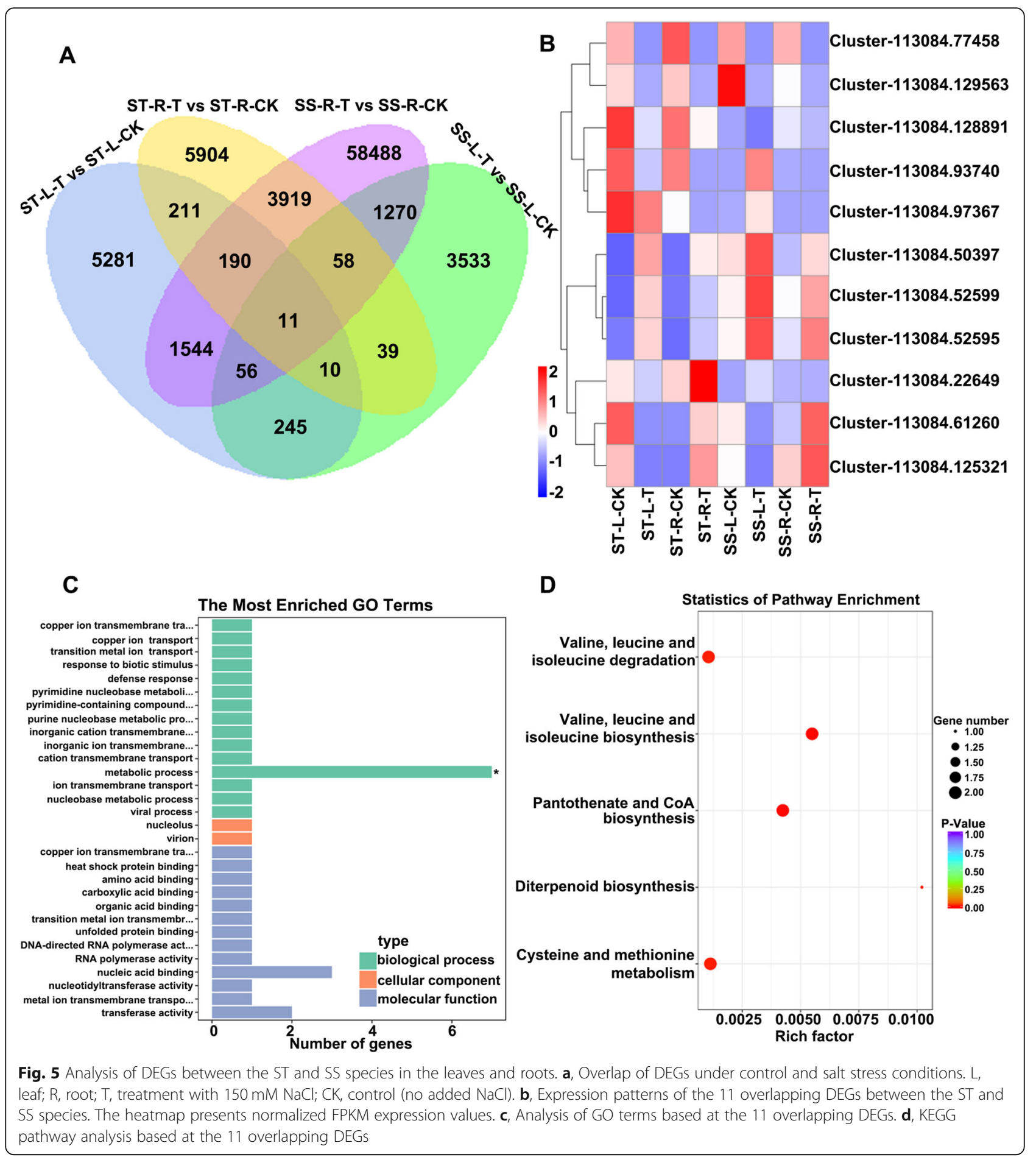

shift in metabolites of ST species under control and salt stress conditions showed that most of pantothenate and CoA biosynthesis signaling-related genes are positively correlated with 3-methyl-2-oxobutanoate, and 3-methyl2 -oxobutanoate was positively correlated with most of genes related to plant hormone signal transduction, valine, leucine and isoleucine metabolism, and starch and sucrose metabolism (Fig. 8). The results of coordinated shift in metabolites of SS species under control and salt stress conditions were opposite to those of ST species (Additional file 1: Figure S7). It is suggested that salt treatment could induce up-regulation of some genes related to a series of metabolic pathways in the ST species, which resulted in a significant increase in the content of 
Table 1 Functional annotation of the 11 overlapping genes between th ST and SS species. NA indicates not available

\begin{tabular}{|c|c|c|}
\hline Gene ID & Function Description & KEGG pathway \\
\hline $\begin{array}{l}\text { Cluster-113, } \\
084.50397\end{array}$ & Outer envelope pore protein $16-2$ & NA \\
\hline $\begin{array}{l}\text { Cluster-113, } \\
084.77458\end{array}$ & ACT domain-containing protein ACR8 & NA \\
\hline $\begin{array}{l}\text { Cluster-113, } \\
084.52599\end{array}$ & $\begin{array}{l}\text { Branched-chain-amino-acid } \\
\text { aminotransferase } 2\end{array}$ & $\begin{array}{l}\text { Valine, leucine and isoleucine metabolismPantothenate and CoA biosynthesisCysteine } \\
\text { and methionine metabolism }\end{array}$ \\
\hline $\begin{array}{l}\text { Cluster-113, } \\
084.128891\end{array}$ & Gibberellin 20 oxidase 2 & Diterpenoid biosynthesis \\
\hline $\begin{array}{l}\text { Cluster-113, } \\
084.61260\end{array}$ & $\begin{array}{l}\text { Probable LRR receptor-like serine/threo- } \\
\text { nine-protein kinase }\end{array}$ & NA \\
\hline $\begin{array}{l}\text { Cluster-113, } \\
084.125321\end{array}$ & Protein argonaute 4 & NA \\
\hline $\begin{array}{l}\text { Cluster-113, } \\
084.129563\end{array}$ & electron transporter, putative & NA \\
\hline $\begin{array}{l}\text { Cluster-113, } \\
084.93940\end{array}$ & Chaperone protein & NA \\
\hline $\begin{array}{l}\text { Cluster-113, } \\
084.52595\end{array}$ & $\begin{array}{l}\text { Branched-chain-amino-acid } \\
\text { aminotransferase } 2\end{array}$ & $\begin{array}{l}\text { Valine, leucine and isoleucine metabolismPantothenate and CoA biosynthesisCysteine } \\
\text { and methionine metabolism }\end{array}$ \\
\hline $\begin{array}{l}\text { Cluster-113, } \\
084.22649\end{array}$ & Short-chain dehydrogenase TIC 32 & NA \\
\hline $\begin{array}{l}\text { Cluster-113, } \\
084.97367\end{array}$ & MLP-like protein 34 & NA \\
\hline
\end{tabular}

3-methyl-2-oxobutanoate to maintain a relatively high content of CoA in ST species. Therefore, the pantothenate and CoA biosynthesis pathways might play an important role in the regulation of salt tolerance in Zygophyllum plants.

\section{Discussion}

Zygophyllum is a genus of mostly perennial and rarely annual herbs in its own family, Zygophyllaceae. There are about 100 species of this genus in the world, mainly distributed in deserts, grasslands and the desertification-

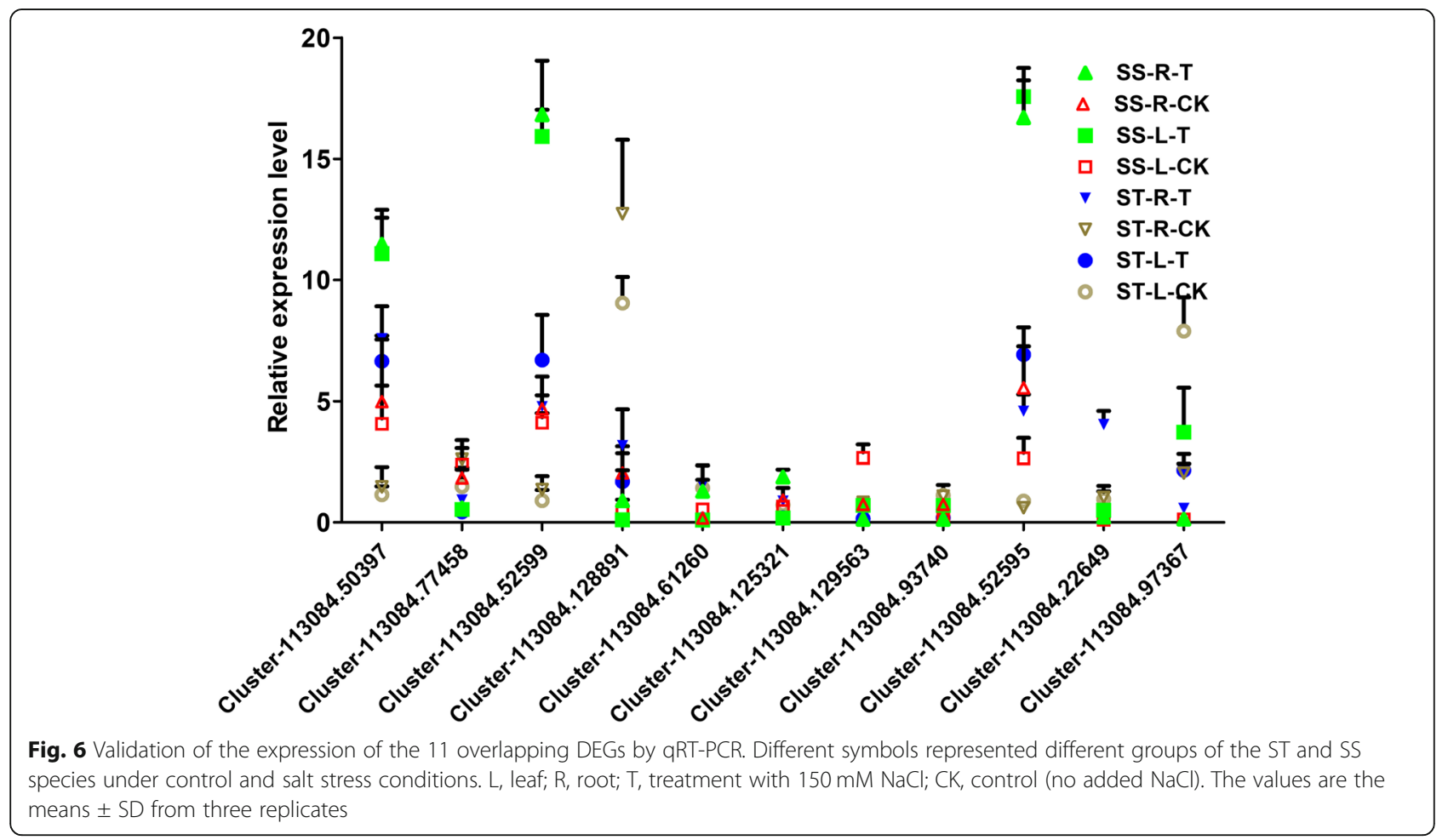



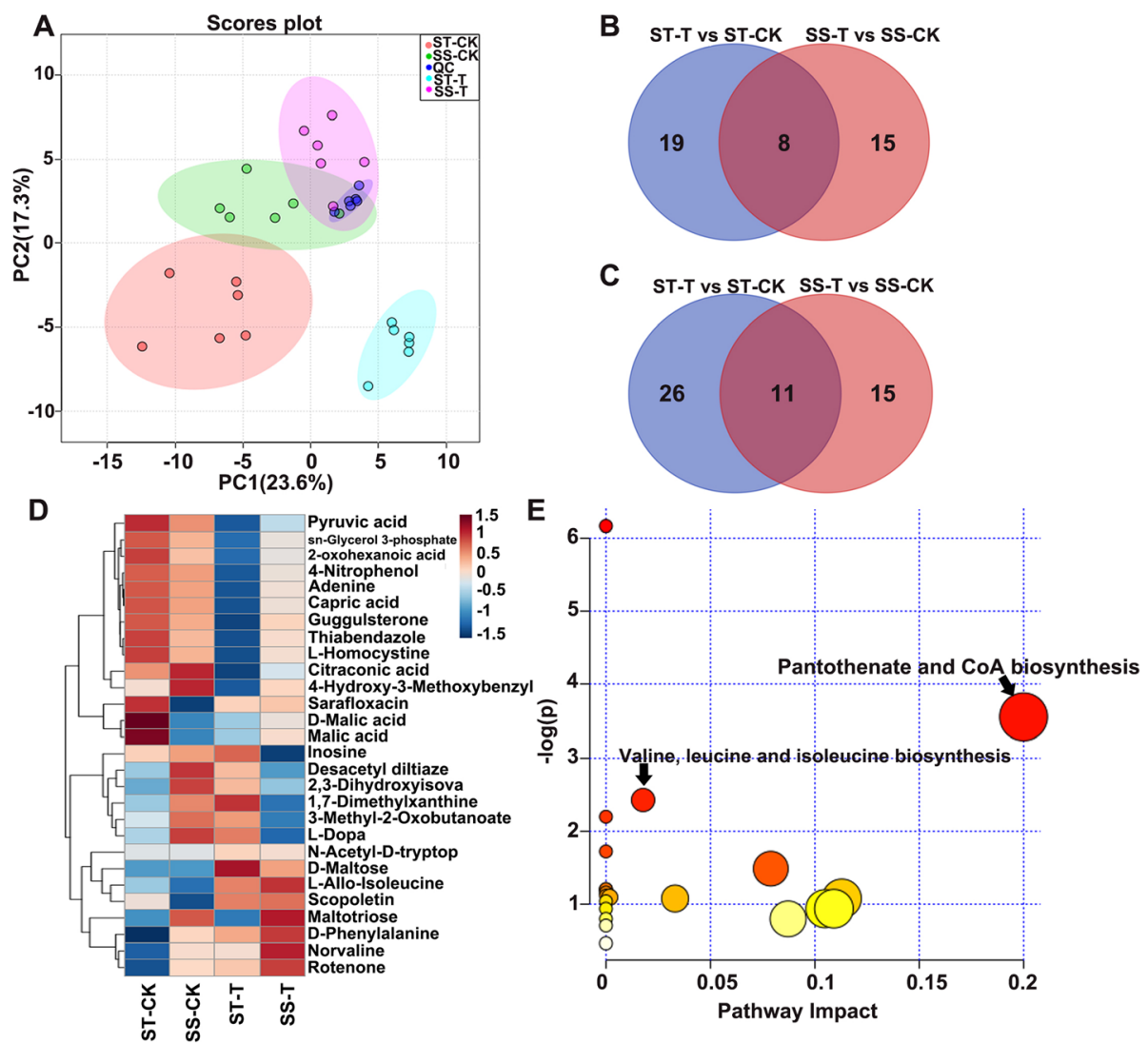

Fig. 7 Metabolomic analysis of differences between the SS and ST species. a, Principal component analysis (PCA) of the metabolic profiles of the ST and SS species under control and salt stress conditions. The explained variance proportions are shown in brackets. QC, quality control. b, Overlap among upregulated metabolites in the ST and SS species under control and salt stress conditions. c, Overlap among the downregulated metabolites in the ST and SS species under the control and salt stress conditions. $\mathbf{d}$, Heatmap illustrating the $\log ^{2}$ (fold change) of selected overlapping differentially abundant metabolites using Euclidean distance measure and average clustering. e, KEGG pathway analysis based at the overlapped different abundant metabolites. T, treatment with $150 \mathrm{mM} \mathrm{NaCl}$; CK, control (no added $\mathrm{NaCl}$ )

affected grassland belt of central Asia, the Mediterranean coast, Africa and Australia [25]. Zygophyllum plants were reported to have certain medicinal value, such as antihypertensive [26], hypoglycemic [27, 28], antiinflammatory and antibacterial activity $[29,30]$. In addition to their medicinal value, Zygophyllum plants also have excellent resistance to stress. Due to the longterm adaptation to the natural arid environment, Zygophyllum possesses excellent resistance to drought, salt, alkali and heavy metals, as well as being tolerant to poor soil, wind erosion, and shifting sands.

In this study, we screened the salt-tolerant species $Z$. brachypterum and the salt-sensitive species $Z$. fabago among three Zygophyllum species. In order to uncover the salt-tolerance mechanism, transcriptomic and metabolic comparisons between $Z$. brachypterum and $Z$. fabago were performed. Interestingly, DEGs in the roots and leaves of the salt-treated groups compared with the respective control groups were significantly enriched in the hormone signal transduction pathways, which indicated that phytohormones might also play an important role in the regulation of Zygophyllum salt tolerance. However, only 11 overlapping DEGs were identified when the DEGs in roots and leaves were combined. Among these, 2 BCATs were significantly enriched in valine, leucine and isoleucine biosynthesis, as well as the pantothenate and CoA biosynthesis pathways. These results indicated that the 11 overlapped DEGs in roots and leaves might affect Zygophyllum salt tolerance by affecting valine, leucine and isoleucine biosynthesis, as well as the pantothenate and CoA biosynthesis pathways.

It has been known for a long time that BCATs catalyse the last step of the synthesis and/or the initial step of the degradation of leucine, isoleucine and valine [31]. The intermediates of branched-chain amino acid biosynthesis are also substrates of pantothenate and CoA synthesis [32]. Furthermore, degradation of branched-chain amino acids by BCATs under drought stress conditions may help maintain the pool of free branched-chain 


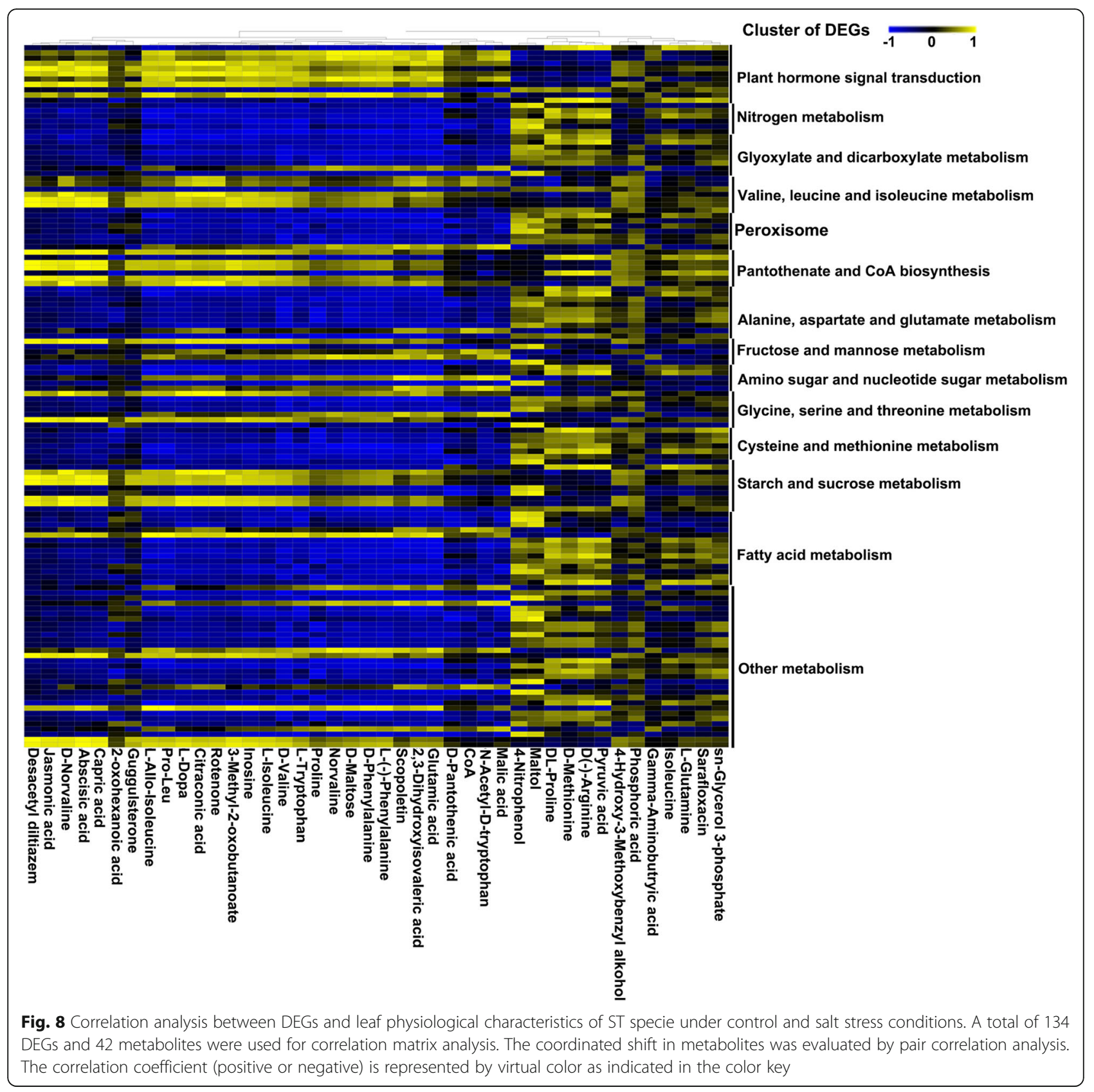

amino acids at low and non-toxic levels [33], which indicated that BCAT genes play an important role in tolerance to abiotic stresses. According to the analysis of the overlapping differentially abundant metabolites between the ST and SS species, the pantothenic acid and CoA biosynthesis pathway was significantly enriched. CoA is an important cofactor in many biosynthesis, degradation and energy generation pathways [34]. Additionally, the CoA biosynthetic enzyme phosphopantetheine adenylyltransferase plays an important role in plant growth, salt/ osmotic stress tolerance and seed lipid storage [35]. In this study, we found that the CoA content was significantly downregulated in the SS species under salt stress, while no significant difference in the CoA content was observed between the ST control and salt-treated groups (Additional file 1: Figure S6C). Based on these findings, we hypothesized on a possible mechanism of salt tolerance regulation in Zygophyllum plants, in which the overexpressed BCATs in the SS salt-treated group could transform 3-methyl-2-oxobutanoate to valine, resulting in a decreased CoA content, which reduced the plants' salt tolerance (Fig. 9). However, whether exogenous CoA or 3-methyl-2-oxobutanoate might improve the salt tolerance of Zygophyllum and the molecular 


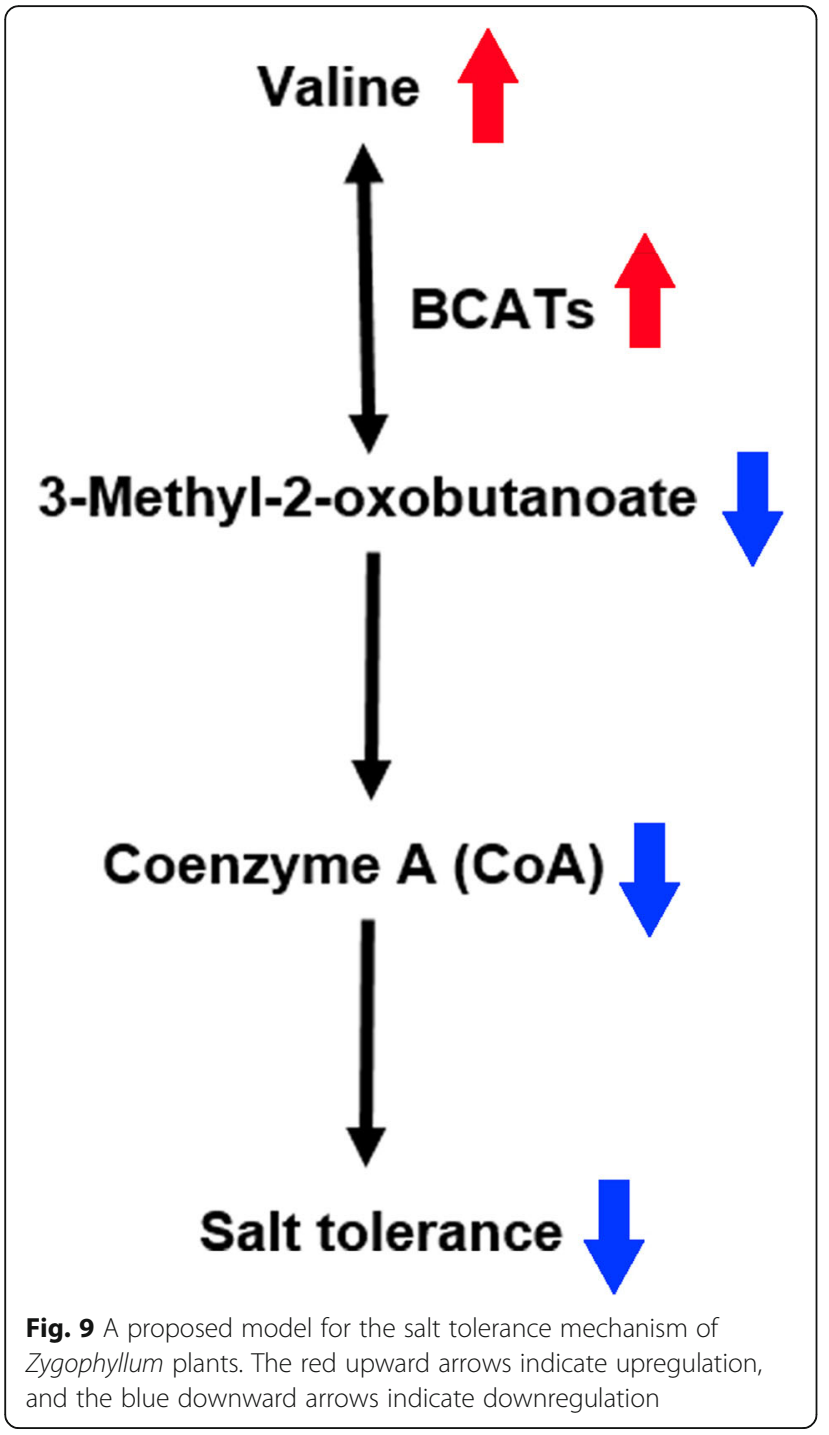

mechanism by which BCATs regulate salt tolerance of Zygophyllum needs to be investigated further in future studies.

\section{Conclusions}

The harsh living environment of Zygophyllum species determines their excellent genetic adaptations to abiotic stress. In this study, we analyzed the differentially expressed genes and differentially enriched metabolites of two Zygophyllum species (the salt-tolerant species $Z$. brachypterum and the salt-sensitive species $Z$. fabago) after salt stress by transcriptomic and metabolomic approaches. We found that the expression of 2 BCAT genes among the 11 overlapping DEGs was significantly induced by salt. These genes were significantly enriched in valine, leucine and isoleucine biosynthesis, as well as the pantothenate and CoA biosynthesis pathways. Moreover, the overlapping differentially abundant metabolites between the ST and SS species were significantly enriched in the pantothenic acid and CoA biosynthesis pathways. Although there was no significant difference in CoA content in the ST species after salt treatment, the CoA content of the SS species decreased significantly after salt treatment. Our results indicate that 2 BCAT genes might affect $\mathrm{CoA}$ biosynthesis to regulate the salt tolerance of Zygophyllum species, possibly contributing a new pathway for improving plant response to salt stress.

\section{Methods}

Seed germination of Zygophyllum spp

Seeds of Zygophyllum brachypterum, Zygophyllum obliquum and Zygophyllum fabago were collected from plants in Xinjiang province, China, and the geographical information of the collection sites was recorded in Additional file 1: Table S3. As Zygophyllum spp. are not endangered, collection of samples for scientific purposes was permitted by local legislation. Professor Li Zhijun, botany major of Tarim University, and Professors Huang Wenjuan and Qiu Aijun, taxonomy major of Tarim University, participated in the identification of specimens. The voucher specimens (TD-00153: Z. brachypterum, TD-01776: Z. obliquum, and TD-00205: $Z$. fabago) are stored in the herbarium of Tarim University, and the data related to the specimens are included in the database of wild plant germplasm resources of the Tarim basin (internal website, not yet open to the public; data available from the corresponding author upon reasonable request).

For seed germination, vermiculite and perlite were mixed at a ratio of 3:1, after which about 100 seeds were buried in the culture substrate, and an adequate amount of water was added to allow the substrate to fully hydrate. The pots were incubated at $26^{\circ} \mathrm{C}$ under a $16 \mathrm{~h} / \mathrm{d}$ light regimen, and water was added at 8:00 AM and 17: $00 \mathrm{PM}$ every day to ensure the normal germination of the seeds.

\section{Histological analysis}

For paraffin sectioning, main stems and leaves at the same position on the main stems of $Z$. brachypterum, $Z$. obliquum and $Z$. fabago were collected at the mature stage of the plants. Paraffin sections were made as described by Ikeda-Kawakatsu et al. [36], with minor modifications as follows: The samples were fixed with FAA (formalin/glacial acetic acid/70\% ethanol (1:1:18)) at $4{ }^{\circ} \mathrm{C}$ overnight, then dehydrated by a graduated ethanol series and a xylene series, and finally embedded in Paraplast Plus and sectioned into $6-\mu \mathrm{m}$ slices using a rotary microtome. The sections were stained with safranin $\mathrm{O}$ fast green and observed under a standard optical microscope. 


\section{Salt treatment of Zygophyllum seedlings}

Before salt treatment, seedlings at the 10-leaf stage were fed with Hoagland nutrient solution [37] for one week to promote growth. In order to reduce the impact of $\mathrm{NaCl}$, a gradual stress treatment was adopted. The indicated amounts of $\mathrm{NaCl}$ were added to Hoagland nutrient solution. The treatments were begun at $50 \mathrm{mM}$, and after $3 \mathrm{~d}$ of adaptation the second stress treatment (100 $\mathrm{mM}$ ) was applied, until the concentration of $\mathrm{NaCl}$ in the Hoagland nutrient solution reached the concentration required for each final treatment. The phenotypic analysis and assessment of physiological indices were performed two weeks after treatment with $200 \mathrm{mM} \mathrm{NaCl}$. Three replicates were performed for each treatment.

\section{Assessment of physiological indices}

Leaves on the same part of the main stem were selected for the assessment of physiological indices. SOD activity was determined using the nitro-blue tetrazolium (NBT) method [38]. POD enzyme activity was determined using the guaiacol method [39]. The CAT content was determined using the ultraviolet absorption method according to Beers and Sizer [40]. Malondialdehyde (MDA) was determined following Dhindsa et al. [41]. The content of chlorophyll was determined using the acetone method [42]. The content of proline was determined according to Bates et al. [43].

\section{RNA preparation and sequencing}

For RNA-seq and metabolite profiling, seedlings of $Z$. brachypterum, Z. obliquum and Z. fabago at the 10-leaf stage were treated with $150 \mathrm{mM} \mathrm{NaCl}$ for $24 \mathrm{~h}$. Total RNA of leaves (on the same part of the main stem) and roots was isolated using the TRIzol reagent (Invitrogen, CA, USA), and treated with DNase I (Invitrogen) for 30 min at $37^{\circ} \mathrm{C}$. RNA degradation and contamination was monitored on $1 \%$ agarose gels. RNA integrity was assessed using the RNA Nano 6000 Assay Kit of the Agilent Bioanalyzer 2100 system (Agilent Technologies, CA, USA). A total amount of $1.5 \mu \mathrm{g}$ RNA per sample was used to generate sequencing libraries using the NEBNext $^{\circ}$ Ultra $^{\mathrm{m}}$ RNA Library Prep Kit for Illumina ${ }^{\circ}$ (NEB, USA). cDNA synthesis, Illumina sequencing and quality control were performed as described by Jiang et al. [44].

Transcriptome assembly was accomplished using Trinity [45] with min_kmer_cov set to 2 and all other parameters set to default. Alternative splicing, allele, different copies of the same gene, homelog, ortholog, etc. were assigned to the same gene because they had the same sequence source. Gene expression levels were estimated using the RSEM software package. The FPKM method was used to calculate the expression levels. Genes with $P$-values $<0.05$ according to the DESeq $R$ package (1.10.1) were assigned as differentially expressed. Gene Ontology (GO) enrichment analysis of the differentially expressed genes (DEGs) was implemented using Wallenius non-central hyper-geometric distribution in the GOseq R package [46]. KOBAS software [47] was used to test the statistical enrichment of differentially expressed genes in KEGG pathways.

\section{Quantitative real-time PCR}

RNA samples for RNA-seq were reverse-transcribed into cDNA using M-MLV reverse transcriptase (Promega). The PCR reactions were performed on a 7500 qRT-PCR system (Applied Biosystems) according to the manufacturer's instructions. The homologous genes of Arabidopsis, Zygophyllum Actin gene (Cluster-113,084.173931), Elf1 gene (Cluster-113,084.196164), and Tubulin gene (Cluster-113,084.111404) were used as internal references, and the gene expression levels were normalized to the geometric average of these internal reference genes as described in previous work [48]. Three biological replicates were performed for each sample. The primers for qRT-PCR are listed in Additional file 1: Table S4.

\section{Metabolite profiling}

Leaves of Z. brachypterum, Z. obliquum and Z. fabago treated with $150 \mathrm{mM} \mathrm{NaCl}$ for $24 \mathrm{~h}$ and those of untreated control plants were harvested for untargeted metabolite profiling based on the LC-MS/MS platform of BIOTREE biotechnology co., LTD. Samples comprising $200 \mathrm{mg}$ were was suspended in either $1.0 \mathrm{ml}$ pure methanol or $1.0 \mathrm{ml} 75 \%$ aqueous methanol for the extraction of lipidsoluble and water-soluble metabolites, respectively. After homogenization in a ball mill, the samples were ultrasonicated on ice and incubated for $1 \mathrm{~h}$ at $-20^{\circ} \mathrm{C}$ to precipitate proteins. Then, the samples were centrifuged at $12,000 \times \mathrm{g}$ for $15 \mathrm{~min}$ at $4{ }^{\circ} \mathrm{C}$, the supernatant transferred into a fresh EP tube, and dried in a vacuum concentrator without heating. The dried powder was reconstituted in extraction liquid reconstitution, vortexed $30 \mathrm{~s}$, and sonicated $10 \mathrm{~min}$, centrifuged at $12,000 \times \mathrm{g}$ for $15 \mathrm{~min}$ at $4^{\circ} \mathrm{C}$. Finally, the supernatant was transferred into a fresh $2 \mathrm{~mL}$ LC/MS glass vial for the UHPLC-QTOF-MS analysis. LC-MS/MS analyses were performed using an UHPLC system (1290, Agilent Technologies) with a UPLC BEH Amide column coupled to a TripleTOF 6600 (Q-TOF, AB Sciex). Raw MS data were processed according to Liao et al. [49]. The quantity of each compound was determined by the ratio of the peak area of a particular component to the peak area of 2-Chloro-L-phenylalanine that was used as an internal control. Additionally, differentially abundant metabolites were extracted based on the values retrieved by Student's $t$-test $(P<0.05)$ and VIP values exceeding 1 (variable importance in the projection, VIP $>1$ ). The 
Venn diagrams were drawn using the Venn tool on the bioinformatics analysis website (http://bioinformatics.psb. ugent.be/webtools/Venn/). Pathway enrichments were calculated using the MetaboAnalyst website (https://www. metaboanalyst.ca/) [50], in conjunction with the Arabidopsis KEGG databases.

\section{Statistical analysis}

For multiple comparisons, one-way ANOVA with Duncan's multiple range test (comparison of all lines) was performed using SPSS software version 23 (IBM Corp., USA). Different letters indicate significant differences at $P<0.05$.

\section{Supplementary information}

Supplementary information accompanies this paper at https://doi.org/10. 1186/s12870-019-2226-8.

Additional file 1: Figure S1. Distribution of transcripts and gene sequences. Figure S2. Volcano maps of the DEGs. DEGs in the leaves of the ST species (A), in the leaves of the SS species (B), in roots of ST (C) and in roots of SS (D) in the control and salt-treated group. The scattered blue dots represent genes with no significant differences, red dots represent significantly up-regulated genes, and green dots represent significantly down-regulated genes. Figure S3. Analysis of DEGs between the ST and SS species in leaves. A, Expression patterns of the overlapping DEGs in leaves between ST and SS under control and salt-treatment conditions. The heatmap presents normalized FPKM expression values. B Analysis of GO terms based at the overlapping DEGs. "** indicated DEGs significantly enriched at $p<0.05$. C, KEGG pathway analysis based at the overlapping DEGs. Figure S4. Analysis of DEGs between the ST and SS species in roots. A, Expression patterns of the overlapping DEGs in roots between ST and SS in the control and salt-treated group. The heatmap presents normalized FPKM expression values. B, Analysis of GO terms based at the overlapping DEGs. "*" indicated DEGs significantly enriched at $p<0.05$.C, KEGG pathway analysis based at the overlapping DEGs. Figure S5. Validation of the expression of selected DEGs in leaves and roots by qRT-PCR. FPKM values of selected DEGs in leaves of the ST and SS species $(\mathbf{A})$ and validation of the expression of these DEGs by GRT-PCR (B). FPKM values of selected DEGs in roots of the ST and SS species $(\mathbf{C})$ and validation of the expression of these DEGs by qRT-PCR (D). Figure S6. Differentially abundant metabolites in the CoA pathway. Content of 3methyl-2-oxobutanoate $(\mathbf{A})$, valine $(\mathbf{B})$ and $\operatorname{CoA}(\mathbf{C})$ in the control and salt-treated groups of the ST and SS species. Figure S7. Correlation analysis between DEGs and leaf physiological characteristics of SS species under control and salt stress conditions. A total of 134 DEGs and 42 metabolites were used for correlation matrix analysis. The coordinated shift in metabolites was evaluated by pair correlation analysis. The correlation coefficient (positive or negative) is represented by virtual color as indicated in the color key. Table S1. Quality assessment of sample sequencing output data. Table S2. Statistical analysis of transcripts and gene sequence lengths. Table S3. Geographical information of the collection sites of Zygophyllum plants used in this study. Table S4. Primers used in this study

\section{Abbreviations}

ABA: Abscisic acid; BCAT: Branched-chain-amino-acid aminotransferase; CAT: Catalase; DEG: Differentially expressed gene; MAPK: Mitogen-activated protein kinase; MDA: Malondialdehyde; NBT: Nitro-blue tetrazolium; POD: Peroxidase; qRT-PCR: Quantitative real-time PCR; SS: Salt sensitive; ST: Salt tolerance; SOS: Salt overly sensitive; SOD: Superoxide dismutase; SEM: Scanning electron microscopy

\section{Acknowledgments}

The authors would like to thank Prof. Li Zhijun, Huang Wenjuan, and Qiu Aijun (Tarim University) for the identification of specimens.

\section{Authors' contributions}

PJ conceived the study and designed the research. JW performed most of the experiments and analyzed the data. XJ and CZ performed the seed germination experiment and tissue section experiment. JW and PJ wrote the manuscript. ZF proposed revision to the manuscript. All authors read and approved the final version of the manuscript.

\section{Funding}

This work was supported by National Natural Science Foundation of China (31660069). The funders had no role in study design, data collection and analysis, or preparation of the manuscript.

\section{Availability of data and materials}

The RNA-Sequencing raw data have been deposited to the National Centre for Biotechnology Information (NCBI) BioProject database under accession number PRJNA560976. All the supporting data are included as additional files.

Ethics approval and consent to participate

Not applicable.

\section{Consent for publication}

Not applicable.

\section{Competing interests}

The authors declared that they have no conflicts of interest to this work.

\section{Author details}

${ }^{1}$ Key Laboratory of Biological Resource Protection and Utilization of Tarim Basin, Xinjiang Production and Construction Group, Alar 843300, China. ${ }^{2}$ College of Life Sciences, Tarim University, Alar 843300, China. ${ }^{3}$ Center of Applied Biotechnology, Wuhan University of Bioengineering, Wuhan 430415, China. ${ }^{4}$ College of Plant Sciences, Tarim University, Alar 843300, China. ${ }^{5}$ State Key Laboratory of Hybrid Rice, Engineering Research Center for Plant Biotechnology and Germplasm Utilization of Ministry of Education, College of Life Sciences, Wuhan University, Wuhan 430072, China. ${ }^{6}$ College of Agricultural Sciences, Guizhou University, Guiyang 550025, China.

Received: 9 September 2019 Accepted: 30 December 2019

Published online: 06 January 2020

\section{References}

1. Zhu J. Abiotic stress signaling and responses in plants. Cell. 2016;167: 313-24.

2. Zhu J. Salt and drought stress signal transduction in plants. Annu Rev Plant Biol. 2002;53:247-73.

3. Munns R. Comparative physiology of salt and water stress. Plant Cell Environ. 2002:25:239-50.

4. Orsini F, D'Urzo M, Inan G, Serra S, Oh D, Mickelbart M, et al. A comparative study of salt tolerance parameters in 11 wild relatives of Arabidopsis thaliana. J Exp Bot. 2010;61:3787-98.

5. Hong Z, Lakkineni $K$, Zhang Z, Verma D. Removal of feedback inhibition of D1-pyrroline-5-carboxylate synthetase results in increased proline accumulation and protection of plants from osmotic stress. Plant Physiol. 2000;122:1129-36

6. Ueda A. Osmotic stress in barley regulates expression of a different set of genes than salt stress does. J Exp Bot. 2004;55:2213-8.

7. Miller G, Suzuki N, Ciftci-Yilmaz S, Mittler R. Reactive oxygen species homeostasis and signaling during drought and salinity stresses. Plant Cell Environ. 2010;33:453-67.

8. Apse $\mathrm{M}$, Sottosanto J, Blumwald E. Vacuolar cation $/ \mathrm{H}^{+}$exchange, ion homeostasis, and leaf development are altered in a T-DNA insertional mutant of AtNHX1, the Arabidopsis vacuolar $\mathrm{Na}^{+} / \mathrm{H}^{+}$antiporter. Plant J. 2003;36:229-39.

9. Garciad G, Fernandezgarcia N, Bardisi E, Pallol B, Asensio-Rubio J, Bru R, et al. New insights into plant salt acclimation: the roles of vesicle trafficking and 
reactive oxygen species signalling in mitochondria and the endomembrane system. New Phytol. 2015;205:216-39.

10. Schachtman D, Liu W. Molecular pieces to the puzzle of the interaction between potassium and sodium uptake in plants. Trends Plant Sci. 1999;4:281-7.

11. Barragán V, Leidi E, Andrés Z, Rubio L, De Luca A, Fernández J, et al. Ion exchangers $\mathrm{NHX} 1$ and $\mathrm{NHX} 2$ mediate active potassium uptake into vacuoles to regulate cell turgor and stomatal function in Arabidopsis. Plant Cell. 2012; 24:1127-42.

12. Maurel C, Verdoucq L, Luu D, Santoni V. Plant aquaporins: membrane channels with multiple integrated functions. Annu Rev Plant Biol. 2008;59:595-624.

13. Sade N, Gebretsadik M, Seligmann R, Schwartz A, Wallach R, Moshelion $M$. The role of tobacco aquaporinl in improving water use efficiency, hydraulic conductivity, and yield production under salt stress. Plant Physiol. 2010;152:245-54.

14. Niewiadomska E, Karpinska B, Romanowska E, Slesak I, Karpinski S. A salinityinduced c3-cam transition increases energy conservation in the halophyte Mesembryanthemum crystallinum L. Plant Cell Physiol. 2004;45:789-94.

15. Song L, Huang S, Wise A, Castanon R, Nery J, Chen H, et al. A transcription factor hierarchy defines an environmental stress response network. Science. 2016;354:1550

16. Verslues P, Agarwal M, Katiyar-Agarwal S, Zhu J, Zhu J. Methods and concepts in quantifying resistance to drought, salt and freezing, abiotic stresses that affect plant water status. Plant J. 2006;45:523-39.

17. Ichimura K. Various abiotic stresses rapidly activate Arabidopsis MAP kinases ATMPK4 and ATMPK6. Plant J. 2000;24:655-65.

18. Dubouzet J, Sakuma Y, Ito Y, Kasuga M, Dubouzet E, Miura S, et al. OSDREB genes in rice, Oryza sativa $\mathrm{L}$, encode transcription activators that function in drought-, high-salt- and cold-responsive gene expression. Plant J. 2003;33:751-63.

19. Guo Y, Halfter U, Ishitani M, Zhu J. Molecular characterization of functional domains in the protein kinase SOS2 that is required for plant salt tolerance. Plant Cell. 2001;13:1383-400.

20. Qiu Q, Guo Y, Dietrich M, Schumaker K, Zhu J. Regulation of SOS1, a plasma membrane $\mathrm{Na}^{+} / \mathrm{H}^{+}$exchanger in Arabidopsis thaliana, by SOS2 and SOS3. Proc Natl Acad Sci U S A. 2002;99:8436-41.

21. Halfter U, Ishitani M, Zhu J. The Arabidopsis SOS2 protein kinase physically interacts with and is activated by the calcium-binding protein SOS3. Proc Natl Acad Sci U S A. 2000:97:3735-40.

22. Lin H, Yang Y, Quan R, Mendoza I, Wu Y, Du W, et al. Phosphorylation of SOS3 LIKE CALCIUM BINDING PROTEIN8 by SOS2 PROTEIN kinase stabilizes their protein complex and regulates salt tolerance in Arabidopsis. Plant Cell. 2009;21:1607-19.

23. Lefèvre I, Vogel-Mikuš K, Jeromel L, Vavpetič P, Planchon S, Arčon I, et al. Differential cadmium and zinc distribution in relation to their physiological impact in the leaves of the accumulating Zygophyllum fabago L. Plant Cell Environ. 2014;37:1299-320

24. Párraga-Aguado I, Gonzalez-Alcaraz M, Alvarez-Rogel J, Jimenez-Carceles $\mathrm{F}$, Conesa $\mathrm{H}$. The importance of edaphic niches and pioneer plant species succession for the phytomanagement of mine tailings. Environ Pollut. 2013;176:134-43.

25. Akhyani V. Flora of Iran, no.7: Zygophyllaceae. Tehran: Research Institute of Forests and Rangelands; 1992.

26. Gibbons S, Oriowo M. Antihypertensive effect of an aqueous extract of Zygophyllum coccineum L. in rats. Phytother Res. 2001;15:452-5.

27. Skim F, Lazrek H, Kaaya A, Amri H, Jana M. Pharmacological studies of two antidiabetic plants: Globularia alypum and Zygophyllum gaetulum. Therapie. 1999:54:711-5.

28. Jaouhari J, Lazrek $H$, Jana M. The hypoglycemic activity of Zygophyllum gaetulum extracts in alloxan-induced hyperglycemic rats. J Ethnopharmacol. 2000:69:17-20.

29. Orhan I, Sener B, Choudhary M, Khalid A. Acetylcholinesterase and butyrylcholinesterase inhibitory activity of some turkish medicinal plants. J Ethnopharmacol. 2004;91:57-60.

30. Zaidi M, Crow S. Biologically active traditional medicinal herbs from Balochistan, Pakistan. J Ethnopharmacol. 2005;96:331-4

31. Stewart $\mathrm{C}$, Beevers $\mathrm{H}$. Gluconeogenesis from amino acids in germinating castor bean endosperm and its role in transport to the embryo. Plant Physiol. 1976;42:1587-95.

32. Singh B, Singh B. Biosynthesis of valine, leucine, and isoleucine in Plant Amino Acids: Biochemistry and Biotechnology, ed. Singh B. K. (Marcel Dekker, New York), 1999.
33. Malatrasi M, Corradi M, Svensson J, Close T, Gulli M, Marmiroli N. A branched-chain amino acid aminotransferase gene isolated fromHordeum vulgareis differentially regulated by drought stress. Theor Appl Genet. 2006; 113:965-76.

34. Begley T, Kinsland C, Strauss E. The biosynthesis of coenzyme a in bacteria. Vitam Horm. 2001;61:157-71.

35. Rubio S, Whitehead L, Larson T, Graham I, Rodriguez P. The coenzyme a biosynthetic enzyme phosphopantetheine adenylyltransferase plays a crucial role in plant growth, salt/osmotic stress resistance, and seed lipid storage. Plant Physiol. 2008;148:546-56.

36. Ikeda-Kawakatsu K, Yasuno N, Oikawa T, lida S, Nagato Y, Masahiko M, et al. Expression level of ABERRANT PANICLE ORGANIZATION1 determines rice inflorescence form through control of cell proliferation in the meristem. Plant Physiol. 2009;150:736-47.

37. Hoagland D. The water-culture method for growing plants without soil. California Agricultural Experiment Station Circular. 1950;347.

38. Jambunathan N. Determination and detection of reactive oxygen species (ROS), lipid peroxidation, and electrolyte leakage in plants. Methods $\mathrm{Mol}$ Biol. 2010;639:292-8

39. Lagriffoul A, Mocquot B, Mench M, Vangronsveld J. Cadmium toxicity effects on growth, mineral and chlorophyll contents, and activities of stress related enzymes in young maize plants (Zea mays L.). Plant Soil. 1998;200:241-50.

40. Beers P, Sizer I. A spectrophotometric method for measuring the breakdown of hydrogen peroxide by catalase. J Biol Chem. 1952;195:133-40.

41. Dhindsa R, Plumb-Dhindsa P, Thorpe T. Leaf senescence: correlated with increased levels of membrane permeability and lipid peroxidation, and decreased levels of superoxide dismutase and catalase. J Exp Bot. 1981; 32:93-101.

42. Zhang H, Liu Y, Xu Y, Chapman S, Love A, Xia T. A newly isolated $\mathrm{Na}^{+} / \mathrm{H}^{+}$ antiporter gene, $D m N H X 1$, confers salt tolerance when expressed transiently in Nicotiana benthamiana or stably in Arabidopsis thaliana. Plant Cell Tiss Org. 2012;110:189-200.

43. Bates $L$, Waldren $R$, Teare I. Rapid determination of free proline for waterstress studies. Plant Soil. 1973;39:205-7.

44. Jiang F, Chen XP, Hu WS, Zheng SQ. Identification of differentially expressed genes implicated in peel color (red and green) of Dimocarpus confinis. Springerplus. 2016;5:1088.

45. Grabherr MG, Haas BJ, Yassour M, Levin JZ, Thompson DA, Amit I, et al. Fulllength transcriptome assembly from RNA-Seq data without a reference genome. Nat Biotechnol. 2011;29:644-52.

46. Young M, Wakefield M, Smyth G, Oshlack A. Gene ontology analysis for RNA-seq: accounting for selection bias. Genome Biol. 2010;11:R14.

47. Mao X, Cai T, Olyarchuk J, Wei L. Automated genome annotation and pathway identification using the KEGG Orthology (KO) as a controlled vocabulary. Bioinformatics. 2005;21:3787-93.

48. Wang J, Wu B, Lu K, Wei Q, Qian J, Chen Y, et al. The amino acid permease OSAAP5 regulates tiller number and grain yield in rice. Plant Physiol. 2019; 180:1031-45.

49. Liao ST, Han C, Xu DQ, Fu XW, Wang JS, Kong LY. 4-Octyl itaconate inhibits aerobic glycolysis by targeting GAPDH to exert anti-inflammatory effects. Nat Commun. 2019;10:5091.

50. Xia J, Mandal R, Sinelnikov I, Broadhurst D, Wishart DS. MetaboAnalyst 2.0-a comprehensive server for metabolomic data analysis. Nucl Acids Res. 2012; 40:127-33.

\section{Publisher's Note}

Springer Nature remains neutral with regard to jurisdictional claims in published maps and institutional affiliations. 